\title{
Aves visitando flores do ipê-amarelo (Handroanthus vellosoi) na área urbanizada ressalta a importância da interação planta-animal na arborização de cidades
}

\author{
Birds visiting flowers of the Yellow Ipe (Handroanthus vellosoi) in the urbanized area emphasizes \\ the importance of plant-animal interaction in the afforestation of cities \\ Las aves que visitan las flores del Ipe Amarillo (Handroanthus vellosoi) en el área urbanizada \\ enfatizan la importancia de la interacción planta-animal en la forestación de ciudades
}

\section{Resumo}

A arborização urbana minimiza os impactos negativos das cidades na biodiversidade. Contudo, a arborização de cidades precisa ser efetiva em promover e manter a biodiversidade e uma abordagem da interação planta-animal parece consistente para tal propósito. Via busca ativa por árvores de ipê-amarelo (Handroanthus vellosoi, Bignoniaceae) floridas, e observação de suas copas, detectamos 31 espécies de aves, de um amplo espectro taxonômico e trófico, visitando suas flores na área urbana e periurbana de uma cidade do Brasil. As aves, destacando seis espécies de beija-flores (polinizadores especializados), consumiram néctar e pétalas independentemente da disponibilidade de flores na copa arbórea, provavelmente em resposta a escassez de flores, frutos carnosos maduros, até insetos, na estação seca. Estimativas de riqueza de espécie sugerem que outros 11 táxons de aves devam se associar as flores de $H$. vellosoi. Uma Análise de Componentes Principais baseada em diferentes índices de diversidade ainda revelou que $H$. vellosoi tem um alto valor de importância para a comunidade de aves visitantes florais de várias bignoniáceas na área urbana. A interação planta-animal aponta que o plantio de $H$. vellosoi é efetivo para promover e manter as aves, inclusive funções ecológicas nas cidades, e.g., polinização pelos beija-flores. Em última análise, a interação planta-animal representa um pano de fundo para consistentemente planejar, criar e restaurar o verde urbano rumo a cidades amigas da natureza.

Palavras-chave: Relações tróficas; Seleção de árvores; Esverdeamento urbano; Conservação da biodiversidade.

\footnotetext{
Abstract

Urban afforestation minimizes the negative impacts of cities on biodiversity. However, afforestation of cities needs to be effective in promoting and maintaining biodiversity and a plant-animal interaction approach seems consistent for this purpose. Through an active search for flowering Yellow-Ipe (Handroanthus vellosoi, Bignoniaceae) trees, and observation of their crowns, we detected 31 bird species from a broad taxonomic and trophic spectrum, visiting their flowers in the urban and peri-urban areas of a city in Brazil. The birds, highlighting six hummingbird species
} 
(specialized pollinators), consumed nectar and petals regardless of the flower crops in the tree crown, probably in response to the scarcity of flowers, ripe fleshy fruits, and even insects in the dry season. Species richness estimates suggest that another 11 avian taxa may be associated with the flowers of $H$. vellosoi. A Principal Component Analysis based on different diversity indices further revealed that $H$. vellosoi has a high importance value for the floral visiting bird community of various bignoniaceous plants in urban areas. The plant-animal interaction indicates that the planting of $H$. vellosoi effectively promotes and maintains birds, including ecological functions in cities, e.g., pollination by hummingbirds. Ultimately, plant-animal interactions provide a background for consistently planning, creating, and restoring urban greenery toward nature-friendly cities.

Keywords: Trophic relationships; Selection of trees; Urban greening; Conservation of biodiversity.

\section{Resumen}

La forestación urbana minimiza los impactos negativos de las ciudades sobre la biodiversidad. Sin embargo, la forestación de ciudades debe ser eficaz para promover y mantener la biodiversidad y un enfoque de interacción plantaanimal parece coherente para este propósito. Mediante una búsqueda activa de árboles en flor de Ipe amarillo (Handroanthus vellosoi, Bignoniaceae) y la observación de sus copas, detectamos 31 especies de aves de un amplio espectro taxonómico y trófico, visitando sus flores en el área urbana y periurbana de una ciudad en Brasil. Las aves, destacando seis especies de colibríes (polinizadores especializados), consumieron néctar y pétalos independientemente de la cantidad de flores en la copa del árbol, probablemente en respuesta a la escasez de flores, frutos carnosos maduros, incluso insectos en la época seca. Las estimaciones de riqueza de especies sugieren que otros 11 taxones de aves pueden estar asociados con las flores de $H$. vellosoi. Un Análisis de Componentes Principales basado en diferentes índices de diversidad reveló además que $H$. vellosoi tiene un valor de gran importancia para la comunidad de aves visitantes florales de varias Bignoniaceae en el área urbana. La interacción planta-animal indica que la plantación de $H$. vellosoi promueve y mantiene eficazmente a las aves, incluidas las funciones ecológicas en las ciudades, por ejemplo, la polinización por colibríes. En última instancia, la interacción planta-animal proporciona un trasfondo para planificar, crear y restaurar de manera consistente la vegetación urbana hacia ciudades amigables con la naturaleza.

Palabras clave: Relaciones tróficas; Selección de árboles; Ecologización urbana; Conservación de la biodiversidad.

\section{Introdução}

Em uma perspectiva ecológica, e de sustentabilidade, as plantas têm óbvia primazia: elas estão envolvidas na produção primária e, portanto, têm uma profunda influência nos ecossistemas (Power, 1992; Fleming \& Kress, 2013; Schuldt et al., 2018). Esclarecendo, as plantas produzem recursos como seiva, folhas, partes florais (cálice, pétalas, estames, estigma), néctar, pólen, néctar extrafloral e frutos (polpa, arilo e semente), os quais servem como fonte de nutrientes e energia para uma variedade de animais consumidores (Janzen, 1980; Fleming \& Kress, 2013). O uso dessas estruturas pelos animais caracteriza interações tróficas de múltiplos tipos e complexidades, antagônicas e não antagônicas (Janzen, 1980; veja capítulos em DelClaro \& Torezan-Silingardi, 2021). Exemplos dessas interações são a herbivoria, proteção anti-herbivoria, florivoria, granivoria, polinização e dispersão de sementes. Fundamentalmente, as interações tróficas planta-animal conectam direta ou indiretamente as espécies e, assim, promovem e mantém a biodiversidade e funções ecossistêmicas (Fleming \& Kress, 2013; Zhang et al., 2018).

Embora ecologicamente importante, a interação planta-animal não tem sido usada como base para planejar, criar, manejar, restaurar e manter o verde urbano, tampouco selecionar árvores para a arborização urbana (Apfelbeck et al., 2020; Silva et al., 2020a). Ao invés disso, a arborização das cidades muitas vezes prioriza os anseios das pessoas, como o valor cultural e estético (Alvey, 2006), sombreamento, conforto térmico e redução do vento (Locke \& Baine, 2015), diminuição de poluição atmosférica, sonora e visual (Mascaró \& Mascaró, 2005), provisão de alimento (Sartori et al., 2019), para citar alguns. A ideia de serviços ecossistêmicos, cujo pano de fundo é o papel da biodiversidade no bem-estar humano (Costanza et al., 1997), fortalece tal suposição, inclusive relativo à arborização urbana (cf. Jones, 2021). Tais condutas não estão erradas, mas afastam-se de ações que efetivamente promovem e mantém a biodiversidade urbana, até mesmo da expectativa em se ter paisagens antrópicas amigas da natureza ou biofílicas (e.g., Melo et al., 2013; Fernandez, 2016). Essas práticas talvez expliquem o uso deliberado de plantas exóticas ou exacerbado de uma única espécie vegetal na arborização urbana (Alvey, 
2006; Sartori et al., 2019).

Cabe notar que a arborização das cidades é geralmente carregada de subjetividades referente à promoção e manutenção da biodiversidade. Como exemplo, uma espécie vegetal é indicada porque atrai aves. Contudo, ela de fato atrai as aves na área urbana? A gama de aves atraídas é variada em termos de diversidade taxonômica e hábitos, e.g., alimentar? Qual é a significância dessa atração, e.g., quanto aos serviços ecossistêmicos: são as aves polinizadores, dispersores, predadores? Em que condição essa atração é relevante, e.g., numa perspectiva sazonal de escassez de alimento, como ocorre na estação seca? A espécie vegetal tem impactos positivos na diversidade de aves na cidade, i.e., exibe um maior valor de importância comparada a outras plantas, portanto, tem destaque ao nível de comunidades?

As áreas urbanas abrangem cerca de 3\% da superfície terrestre (Liu et al., 2014). Embora pareça insignificante, esse percentual crescerá nos próximos anos, pois, estima-se que 5,2 bilhões de pessoas viverão nas cidades até 2030 (UNPD, 2018). Isso significa um aumento na demanda de ambientes construídos, portanto, de destruição ou mudanças na paisagem natural, o que ameaça a biodiversidade (McDonald et al., 2019). Além disso, o crescimento urbano perpetua um sistema econômico que, na maioria das vezes, influencia a perda de hábitats ou reduz a qualidade dos ambientes remanescentes (Güneralp \& Seto, 2013; McDonald et al., 2019). Por exemplo, a vida na cidade demanda produtos alimentícios e tecnológicos (Rees \& Wackernagel, 1996). Presumivelmente, com o crescimento urbano, mais terras serão requeridas para a produção de alimento e industrialização (Angel et al., 2012; McDonald et al., 2019). É provável então que ambientes naturais intactos sejam cada vez mais escassos no futuro (Chazdon et al., 2009). Ressalta-se que, como um ser pensante que projeta o futuro, o homem tem o dever de compartilhar o planeta com outras espécies e assim promover e manter a biodiversidade (e.g., Wilson, 2016).

Durante muito tempo, a principal forma, mas não exclusiva, de promover e manter a biodiversidade, permeou a implantação de Áreas Protegidas ou Unidades de Conservação (Rodrigues et al., 2004). Embora tal estratégia permaneça indispensável (Wilson, 2016), especialmente no Brasil (veja Vieira et al., 2019), um novo paradigma conservacionista emergiu recentemente: a conservação da biodiversidade em paisagens antropogênicas (Chazdon et al., 2009), inclusive urbanizadas (Goddard et al., 2010; Kowarik, 2011; Lepczyk et al., 2017). É paradoxal, mas certas áreas urbanas têm sido reconhecidas como hotspots ou mesmo fontes de biodiversidade e serviços ecossistêmicos (Ives et al., 2016; Shaffer, 2018; Silva et al., 2020b). Na verdade, muitas cidades estão alocadas em regiões naturalmente ricas em espécies da fauna e flora (Alvey, 2006). Como resultado, várias espécies da vida selvagem estão se estabelecendo nas cidades, talvez porque são forçadas a isso, mas também devido a um aumento na qualidade ambiental urbana (Shaffer, 2018). Parece que a arborização das cidades tem um papel fundamental para melhorar a qualidade do ambiente construído, significando uma força promotora e mantenedora da biodiversidade urbana (Alvey, 2006; Threlfall et al., 2017). Contudo, precisamos de maneiras mais consistentes de seleção de espécies arbóreas visando promover e manter a biodiversidade urbana, em vez de priorizar aspirações humanas, inclusive para atenuar subjetividades nesse papel da arborização nas cidades.

Aqui, apresentamos a interação planta-animal como um modelo consistente de seleção de espécies vegetais arbóreas para a arborização urbana, objetivando a promoção e manutenção da biodiversidade nas cidades. Para isso, ilustramos um estudo de caso envolvendo as interações de aves com as flores do ipê-amarelo, Handroanthus vellosoi (Toledo) Mattos (Bignoniaceae), em uma cidade do oeste paulista, Brasil. O modelo em si é providencial, pois espécies de Bignoniaceae, em sua maioria de ipês, bem como de aves, compõem múltiplos ambientes das cidades Brasileiras. Nossa abordagem inicial é puramente ecológica, mas usamos isso como um pano de fundo para promover cidades mais amigas da biodiversidade (ou biofílicas), uma das agendas da biologia de conservação e da sustentabilidade (Shaffer, 2018; Apfelbeck et al., 2020; Knapp et al., 2021). Damos um enfoque aos seguintes parâmetros, os quais têm alta significância ecológica: a) diversidade taxonômica das aves visitantes florais; b) suas respectivas guildas tróficas e hábitos, o que remete aos papéis funcionais; c) seus comportamentos durante as visitas as flores; e d) oferta de flores numa perspectiva sazonal, i.e., em tempos de escassez geral 
de alimento na estação seca. Como um complemento, realizamos uma abordagem quantitativa no sentido de verificar se, em meio a outras espécies de Bignoniaceae, H. vellosoi têm maior ou menor valor de importância para diversidade de aves visitantes florais na cidade, o que indica o papel desse ipê em escala de comunidade.

\section{Metodologia}

\section{1 Área de estudo}

Desenvolvemos este estudo na área urbana e periurbana da cidade de Ilha Solteira, localizada no extremo oeste do estado do São Paulo, sudeste do Brasil (20²5’S, 5120'W; 380 m a.s.l), nas confluências dos Rios São José dos Dourados e Tietê com o Rio Paraná. Trata-se de uma cidade pequena, com cerca de 26 mil habitantes, majoritariamente vivendo na área urbana. Ilha Solteira está inserida em uma região biogeográfica relevante, i.e., de transição entre os biomas Mata Atlântica e Cerrado (Ab'Sáber, 2012), dois hotspots brasileiros de biodiversidade (cf. Myers et al., 2000). Esta característica espacial de ecótono tem influência positiva na diversidade de organismos, sobretudo na diversidade de aves (Kark et al., 2006). O clima da região é sazonal, com chuvas entre outubro e março e secas entre abril e setembro, com pico em julho e agosto. Sintomaticamente na estação seca, a maioria das espécies vegetais nativas perde suas folhas, e, flores e frutos carnosos são geralmente escassos (Silva, 2019).

A paisagem é dominada por áreas de cultivo agrícola, sobretudo de cana-de-açúcar. Também há áreas representativas de pastagens e horticultura em pequenos sítios ao redor da cidade (cinturão verde) e assentamentos rurais. Apenas 6,1\% da área do município é coberta por algum tipo de vegetação natural (Instituto Florestal, 2020), como fragmentos de Floresta Estacional Semidecídua, Mata Seca, Mata de Galeria, Mata Ciliar e Campo Úmido. Há ainda savanas, i.e., uma mescla de áreas regeneradas com espécies vegetais exóticas e nativas.

Fragmentos florestais dominados pela árvore exótica Leucena (Leucaena leucocephala (Lam.) R. de Wit, Fabaceae) são comuns ao redor ou entremeando a cidade. Também há reflorestamentos heterogêneos adjacentes a corpos d'água que penetram ou atravessam bairros da cidade. Ruas, avenidas, rotatórias, estacionamentos, perímetro urbano, praças, parques, áreas verdes, jardins residenciais, universidades, escolas, clubes e o cemitério apresentam uma variedade de espécies vegetais exóticas e nativas, de hábitos herbáceos, arbustivos, trepadeiras, e sobretudo arbóreos. Dentre as árvores, destaca-se a Família Bignoniaceae, com vários indivíduos pertencentes a espécies nativas conhecidas como ipê, piúva, pau-d'arco e jacarandá. Exemplos são, em ordem de representatividade de árvores plantadas: Handroanthus impetiginosus (Mart. ex DC.) Mattos (ipêroxo ou pau-d'arco-roxo), Handroanthus chrysotrichus (Mart. ex A. DC.) Mattos (ipê-amarelo ou ipê-amarelo-paulista), Jacaranda cuspidifolia Mart. (jacarandá-de-minas), Tabebuia roseoalba (Ridl.) Sandwith (ipê-branco), Handroanthus heptaphyllus (Vell.) Mattos (ipê-roxo ou piúva), Handroanthus vellosoi (Figura 1), Handroanthus serratifolius (Vahl) S.O. Grose (piúva-amarela ou pau-d'arco-amarelo), Handroanthus ochraceus (Cham.) Mattos (ipê-do-cerrado) e Cybistax antisyphilitica (Mart.) Mart. (ipê-verde). Também há bignoniáceas exóticas de abundância considerável como Tecoma stans (L.) Juss. ex Kunth (ipê-amarelo-de-jardim) e, mais raramente, Spathodea campanulata P. Beauv. (espatódea). 
Figura 1. Dois exemplares de Handroanthus vellosoi, um maior e um menor à esquerda, plantados na calçada em frente a uma residência na área urbana de Ilha Solteira. Note a maciça floração na copa da árvore maior, a qual recebeu nota 4 (ver sessão 2.3) em termos de intensidade de fenofase floral. As flores amarelas evidenciam o atributo bem ornamental que o ipê tem.

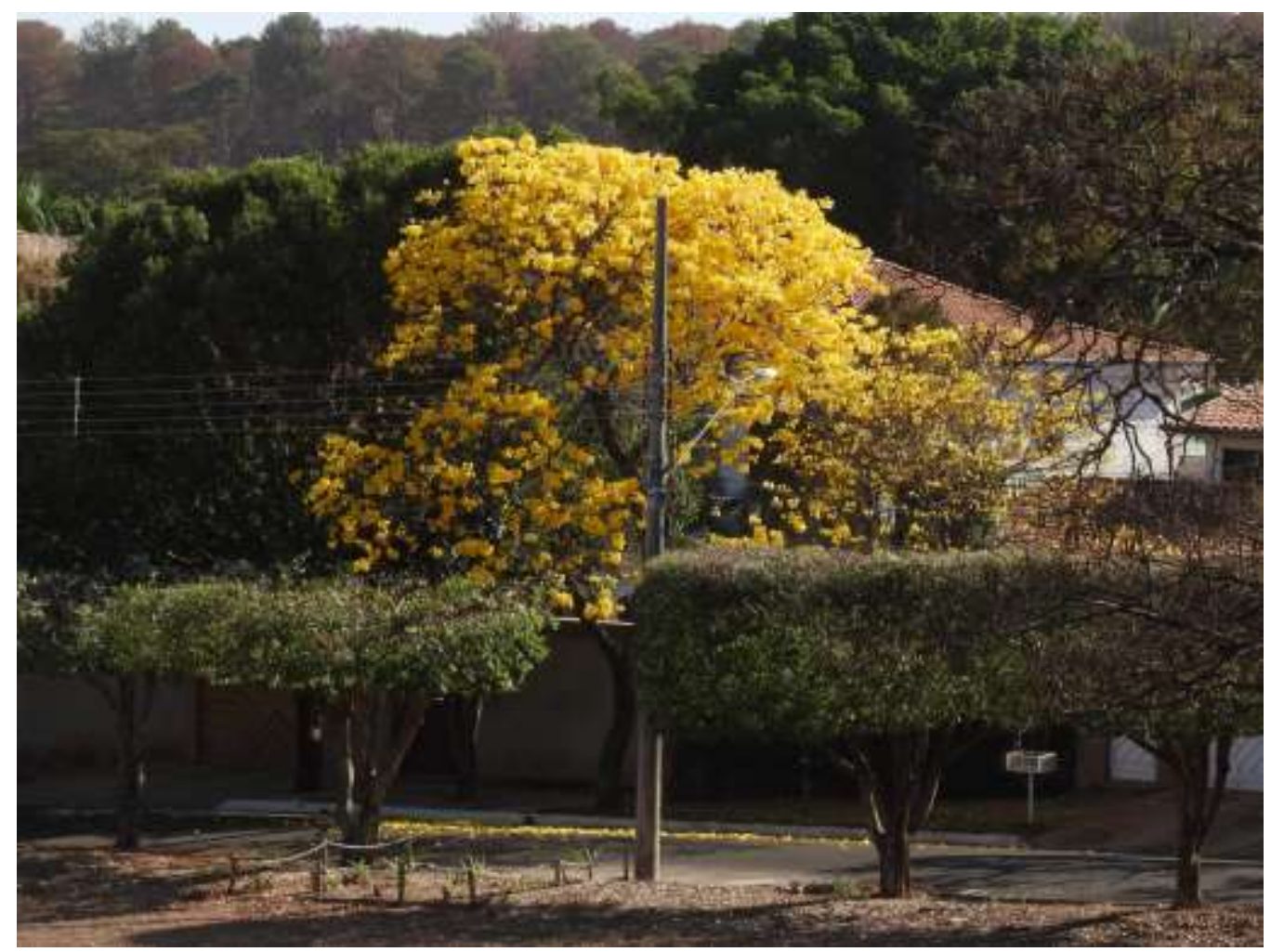

Fonte: Autores (2021).

\subsection{Atributos de Handroanthus vellosoi e história de uso local como ornamental}

Handroanthus vellosoi é nativa e endêmica do Brasil (Lohmann, 2020). Este ipê chega a $25 \mathrm{~m}$ de altura (comumente 10-15 m) e é encontrado nos estados de São Paulo, Minas Gerais, Rio de Janeiro e Sul do Paraná, na floresta pluvial e semidecicual da Mata Atlântica e ambientes do Cerrado (Lorenzi, 2008; Lohmann, 2020). Como muitas espécies de Bignoniaceae (veja Gentry, 1974), os indivíduos de H. vellosoi tem floração maciça, exuberante e sincronizada, com a planta sem folhas, o que eleva sua conspicuidade e aspecto ornamental (cf. Figura 1). A floração é tida como anual e ocorre na estação seca, entre julho e setembro (Lorenzi, 2008). Contudo, a floração pode se estender de acordo com a intensidade e amplitude da estação seca. Por exemplo, em Ilha Solteira, em anos bem secos, há plantas que florescem desde maio, até meados de outubro. Além disso, enquanto não chove, a mesma árvore pode florescer mais de uma vez (padrão bianual). As flores, do tipo "goela", com corola amarelo-dourada listrada de vermelho, afunilada formando um tubo alongado, são relativamente grandes e produzidas em inflorescências do tipo capítulo. O néctar é produzido em uma câmara nectarífera situada na base do tubo da corola, i.e., no cálice verde. $\mathrm{O}$ atributo da flor sugere síndrome de melitofilia, i.e., polinizada por abelhas, o que é comum nos ipês dos gêneros Handroanthus e Tabebuia (Vitali \& Machado, 1995; Barros, 2001; Souza et al., 2004; Gandolphi \& Bittencourt Jr., 2010; Acra et al., 2012; Parrini \& Pacheco, 2013).

Handroanthus vellosoi tem um histórico de cultivo como ornamental em Ilha Solteira (Companhia Energética de São Paulo, 1986). Essa cidade foi planejada para alojar trabalhadores envolvidos na construção da Usina Hidrelétrica de Ilha Solteira na década de 1970. Nos idos de 80 e 90, havia pelo menos uma árvore de H. vellosoi plantada a cada duas casas germinadas, em praticamente todas as vielas não pavimentadas da cidade. Além disso, muitos indivíduos remanescentes de desmatamentos realizados entre 1970 e 1980 foram preservados em vários pontos da cidade. Todas as árvores das vielas foram 
removidas em função da pavimentação, isso no início da década de 90. Muitas daquelas árvores poupadas nos desmatamentos já morreram ou caíram devido a tempestades localmente comuns entre outubro e dezembro. Hoje, H. vellosoi ainda é localmente cultivada como ornamental, plantada adjacente ou de fronte a residências (cf. Figura 1), as vezes compondo praças, também canteiros centrais em avenidas. Este ipê ainda compõe o perímetro urbano, onde os espécimes plantados servem como fonte de sementes para a regeneração natural. O cultivo de $H$. vellosoi não é dificultoso. Cada fruto (uma cápsula alongada deiscente) contém várias sementes que germinam em taxas superiores a $60 \%$, em 6 a 12 dias, e as mudas crescem rápido e podem ser plantadas em menos de seis meses (Lorenzi, 2008). Apesar disso, provavelmente devido ao porte mais elevado, $H$. vellosoi tem sido localmente substituída por outras espécies de ipê-amarelo de menor porte, como H. chrysotrichus.

\subsection{Procedimentos no campo}

Estudamos as interações entre aves e flores de H. vellosoi combinando as metodologias de transecções lineares e árvore focal (Machado \& Rocca, 2010). Em diferentes dias ( $\mathrm{n}=15)$ de agosto e setembro de 2021, entre 07:00 e 11:00 h e 15:00 e 18:00 h, nós percorremos ruas e o perímetro urbano em busca de plantas de H. vellosoi florescendo. Ao encontrar uma planta com flores, realizamos uma sessão de observação em sua copa, a qual durou 90 minutos. Nesse período, registramos a ave ou grupo de aves que interagiu com as flores para consumir néctar e/ou pétalas. Consideramos o registro de cada ave como sendo uma visita, e se uma ave deixasse a copa arbórea, mas retornasse em seguida, uma nova visita era anotada (veja o método feeding bout em Altman, 1974, adaptado em Galetti, 2002). Também observamos se a ave interagia com a flor de forma antagônica ou não antagônica, o que possibilitou formular e anotar quatro categorias de visitas. Nas interações antagônicas, com o bico, a ave perfura a corola afunilada e/ou cálice floral para obter o néctar (categoria pilhador), ou então remove e manipula a flor para acessar tal recurso (categoria predador), ou ainda consome as pétalas parcialmente ou por inteiro (categoria danificador). Nas visitas não antagônicas, ou mutualísticas, a ave insere o bico na abertura da corola e toca os órgãos reprodutivos (estames e estigma), potencialmente polinizando a flor enquanto consome o néctar (categoria polinizador). A classificação taxonômica das aves seguiu Pacheco et al. (2021) e, a guilda trófica, Sick (1997).

\subsection{Análises}

Nós avaliamos a intensidade da floração, portanto, de disponibilidade de flores para as aves, em cada árvore encontrada. Para isso, usamos o Índice Percentual de Intensidade de Fournier (Fournier, 1974), que consiste em examinar a presença de flores em um percentual da área da copa arbórea. Assim, atribuímos notas variando de 1 a 4, onde: 1 = flores em 1 a $25 \%$ da copa arbórea; $2=$ flores em 26 a $50 \%$ da copa; $3=$ flores em 51 a $75 \%$ da copa; 4 = flores em 76 a $100 \%$ da copa arbórea (cf. Figura 1). Todas as categorias de intensidade atribuídas foram somadas e depois divididas pela soma máxima que poderia ser atribuída à população (total de árvores observadas multiplicado por 4, a categoria de intensidade superior). $\mathrm{O}$ valor obtido corresponde a uma proporção que, multiplicado por 100, é transformado em um valor percentual que denota a intensidade da floração, ou disponibilidade de flores, em um nível populacional. Variações nas atividades de visitas de acordo com a categoria de intensidade de floração foram avaliadas usando o Teste Qui-quadrado.

Nós construímos uma curva de rarefação de espécies baseada no número de aves detectadas em cada sessão de observação. Ressalta-se que tal número consiste apenas na primeira observação, ou seja, aqueles registros subsequentes enquanto os mesmos indivíduos deixavam e retornavam a copa arbórea não foram incluídos nessa análise. Neste caso, como consideramos cada ave como sendo uma visita, e usamos o método de feeding bout, o total de vistas excede o de indivíduos. O objetivo de tal análise é predizer a diversidade, i.e., número de espécies de aves que poderia estar associada às flores de $H$. vellosoi. Esta riqueza também foi predita via emprego de técnicas não paramétricas, como Jackknife 1 e 2, Bootstrapping (Smith \& Van Belle, 1984) e Chao2 (Chao, 1987). 
Por fim, usamos uma abordagem quantitativa para verificar a importância relativa de $H$. vellosoi ao nível de comunidades de aves visitantes de flores de bignoniáceas, majoritariamente de ipês, cultivadas na área urbana e periurbana de Ilha Solteira. Tais táxons têm um forte impacto na disponibilidade de flores (i.e., via fenologia floral) na cidade, o que é determinante para manter interação aves-flores na área urbana (caso de beija-flores; cf. Vitorino et al., 2021). Para isso, combinamos os dados deste estudo com dados de visitas florais pelas aves obtidas em uma investigação de longo prazo (18 anos, i.e., 2003-2021) na área urbana e periurbana de Ilha Solteira, também via método planta focal. Assim, além de $H$. vellosoi, essa análise abrangeu as bignoniáceas arbóreas Jacaranda cuspidifolia, Handroanthus chrysotrichus, H. heptaphyllus, H. impetiginosus, H. serratifolius, Spathodea campanulata, Tabebuia roseoalba, e Tecoma stans. Ainda incluímos uma outra espécie de bignoniácea, Pyrostegia venusta (Ker Gawl.) Miers (cipó-de-são-joão), trepadeira cujas flores são bastante visitadas pelas aves no perímetro urbano.

A importância relativa foi mensurada calculando-se 11 índices de diversidade: Dominance_D; Simpson_1-D; Shannon_H; Evenness_e^H/S; Brillouin; Menhinick; Margalef; Equitability_J; Fisher_alpha; Berger-Parker; e Chao-1 (cf. explicações de tais índices em Harper, 1999; Magurran, 2019). As correlações entre estes índices foram avaliadas usando o Coeficiente de Correlação de Pearson, e os valores mostraram-se fortemente correlacionados $(p<0,01)$. Para então reduzir vieses nas análises em função dessa multicolinearidade, nós empregamos a técnica multivariada de Análise de Componentes Principais (PCA em inglês) sobre os valores dos índices de diversidade calculados. Um novo índice foi gerado, o qual sintetiza a importância de cada espécie de bignoniácea acima citada. O primeiro eixo, i.e., PC1, explicou 96,45\% da variação nas plantas. Portanto, foi usado como um índice que expressa a intensidade com a qual cada uma das bignoniáceas influencia (potencialmente mantém) a diversidade de aves na área urbana e periurbana via interação trófica.

\section{Resultados e Discussão}

Nós encontramos 30 árvores de $H$. vellosoi em episódios de floração na área urbana e periurbana de Ilha Solteira. Portanto, os dados de interação aves-flores aqui provêm de 30 sessões de observação, 45 horas de estudo focado na copa desse representante de ipê-amarelo. Todas as árvores se enquadraram em uma das quatro categorias de intensidade de fenofase de floração: seis com notas 1, 2 ou 3, e 12 com a nota 4. Isso resultou em uma intensidade de $70 \%$ na fenofase de floração ao nível da população. Portanto, $H$. vellosoi estava no pico de floração durante o período de estudo, mas a disponibilidade de flores era moderadamente abundante, não maciça como é comum nas Bignoniaceae (e.g., Gentry, 1974; Ragusa-Netto, 2005). Ainda assim, registramos 751 visitas florais realizadas por um amplo espectro taxonômico de aves (31 espécies pertencentes a 10 famílias e 13 subfamílias), de guildas tróficas variadas, as quais consumiram néctar e/ou pétalas (Tabela 1). 
Tabela 1. Aves visitando as flores de Handroanthus vellosoi em área urbana e periurbana de Ilha Solteira, estado de São Paulo, Brasil (ordem taxonômica de acordo com Pacheco et al., 2021). ${ }^{\text {a }} \mathrm{F}=$ frugívoro; $\mathrm{G}=$ granívoro; $\mathrm{I}=$ insetívoro; $\mathrm{N}=$ nectarívoro; $\mathrm{O}=$ onívoro. ${ }^{\mathrm{b}} \mathrm{n}=$ néctar; $\mathrm{p}=$ pétalas. ${ }^{\mathrm{c}} \mathrm{Da}=$ danificador; $\mathrm{Pi}=$ pilhador; $\mathrm{Po}=$ polinizador; $\mathrm{Pr}=$ predador.

\begin{tabular}{lllll}
\hline Família, Subfamília e Espécie & Nome comum & Guilda $^{\mathrm{a}}$ & Freq. visitas $(\%)$ Item $^{\mathrm{b}}$ & Categoria $^{\mathrm{c}}$
\end{tabular}

Trochilidae (beija-flores)

\section{Polytminae}

Polytmus guainumbi (Pallas, 1764)

beija-flor-de-bico-curvo

$\mathrm{N}$

0,80

$\mathrm{n}$

$\mathrm{Pi} / \mathrm{Po}$

Trochilinae

Heliomaster furcifer (Shaw, 1812)

Chlorostilbon lucidus (Shaw, 1812)

Eupetomena macroura (Gmelin, 1788)

Hylocharis chrysura (Shaw, 1812)

Chionomesa fimbriata (Gmelin, 1788)

Ramphastidae (tucanos)

Ramphastos toco Statius Muller, 1776

Picidae (pica-paus)

Picumninae

Picumnus albosquamatus d'Orbigny, 1840

Psittacidae (papagaios)

Arinae

Brotogeris chiriri (Vieillot, 1818)

Alipiopsitta xanthops (Spix, 1824)

Amazona aestiva (Linnaeus, 1758)

Forpus xanthopterygius (Spix, 1824)

Eupsittula aurea (Gmelin, 1788)

Ara ararauna (Linnaeus, 1758)

Turdidae (sabiás)

Turdus leucomelas Vieillot, 1818

Mimidae (sabiás-do-campo)

Mimus saturninus (Lichtenstein, 1823)

Passeridae (pardais)

Passer domesticus (Linnaeus, 1758)

Fringillidae (fim-fim)

Euphoniinae

Euphonia chlorotica (Linnaeus, 1766)

Icteridae (pássaros-preto)

\section{Cacicinae}

Cacicus haemorrhous (Linnaeus, 1766)

\section{Icterinae}

Icterus pyrrhopterus (Vieillot, 1819)

\section{Agelaiinae}

Molothrus rufoaxillaris Cassin, 1866

Molothrus bonariensis (Gmelin, 1789)

Gnorimopsar chopi (Vieillot, 1819) bico-reto-azul

besourinho-de-bico-vermelho

$\mathrm{N}$

beija-flor-tesoura

beija-flor-dourado

beija-flor-de-garganta-verde

tucanuçu

picapauzinho-squamoso

I

0,53

4,66

6,26

7,32

7,99

4,66

0,27

$\mathrm{p}$

$\operatorname{Pr}$

periquito-de-encontro-amarelo
papagaio-galego
papagaio-verdadeiro
tuim
periquito-rei

F-G

4,93

0,40

F-G

F-G

2,53

F-G

0,53

F-G

4,93

F-G

0,40

O

0,40

n-p

$\mathrm{Da} / \mathrm{Pi}$

sabiá-do-campo

O

2,0

n-p

$\mathrm{Da} / \mathrm{Pi}$

pardal

O

0,79

n-p

$\mathrm{Da} / \mathrm{Pi}$

fim-fim

F-I

0,53

n-p

$\mathrm{Da} / \mathrm{Pi}$

guaxe

O

6,39

$\mathrm{n}$

$\mathrm{Pi} / \mathrm{Pr}$

encontro

O

11,19

n

$\mathrm{Pi} / \mathrm{Pr}$

chupim-azeviche

$\mathrm{O}$

0,67

Pi

chupim
0,67

4,79

$\mathrm{Pi}$

$\mathrm{O}$

$\begin{array}{cc}\text { n } & \text { Pi } \\ \text { n } & \text { Pi } \\ \text { n-p } & \mathrm{Da} / \mathrm{Pi} / \mathrm{Pr}\end{array}$

Thraupidae (sanhaços, saís, coleiros, canários)

Dacninae 
Dacnis cayana (Linnaeus, 1766)

\section{Coerebinae}

Coereba flaveola (Linnaeus, 1758)

\section{Sporophilinae}

Sporophila caerulescens (Vieillot, 1823)

Sporophila leucoptera (Vieillot, 1817)

\section{Diglossinae}

Conirostrum speciosum (Temminck, 1824)

Sicalis flaveola (Linnaeus, 1766)

\section{Thraupinae}

Thraupis sayaca (Linnaeus, 1766)

Stilpnia cayana (Linnaeus, 1766)

\begin{abstract}
saí-azul
\end{abstract}
cambacica

coleirinho

chorão

figuinha-de-rabo-castanho

canário-da-terra

sanhaço-cinzento

saíra-amarela
Fonte: Autores (2021).
N-I

N-I

G

G

2,26

$n-p$

n-p Da/Pi

0,13

n

Pi

Pi

F-

G

0,27

1,33

n-p

$\mathrm{Da} / \mathrm{Pi}$

n-p $\quad \mathrm{Da} / \mathrm{Pi}$

F-I $\quad 10,39 \quad n-p \quad D a / P i$

i
$/ \mathrm{Pi}$
$/ \mathrm{Pi}$
$/ \mathrm{Pi}$
$/ \mathrm{Pi}$
$\mathrm{Pi}$

Thraupidae (sanhaços; 8 espécies), Psittacidae (papagaios; 6 espécies), Trochilidae (beija-flores; 6 espécies), Icteridae (pássaros-preto; 5 espécies) e Passeridae (pardal; 1 espécie), foram as famílias mais frequentemente observadas interagindo com as flores (Figura 1; Tabela 1). As demais famílias estão representadas por uma única espécie (Tabela 1) e são visitantes infrequentes, com menos de 5\% das visitas (Figura 3a). Tais registros mostram paralelos com outros estudos em termos de grupos taxonômicos interagindo com flores de espécies de ipês. Por exemplo, há relatos na literatura de uma variedade de beija-flores, papagaios, pássaros-preto e sanhaços, dentre outros, visitando flores de Tabebuia spp. (Willis, 2002; Mendonça \& Anjos, 2005), Tabebuia aurea (Ragusa-Netto, 2005; Mendes et al., 2017), Handroanthus serratifolius (Melo et al., 2009), H. heptaphyllus (Parrini \& Pacheco, 2013; Marcon, 2016), H. ochraceus (Moura \& Corrêa, 2015), H. chrysotrichus (Marcon, 2016) e H. impetiginosus (Lunardi et al., 2019). Como nenhum estudo havia abordado H. vellosoi, nossos registros colocam essa bignoniácea no rol de espécies de ipês importantes na atração de um conjunto também variado de aves.

Figura 2. Diversidade taxonômica de aves, em termos de Família, e suas respectivas frequências de visitas (em porcentagem) às flores de Handroanthus vellosoi na área urbana e periurbana de Ilha Solteira.

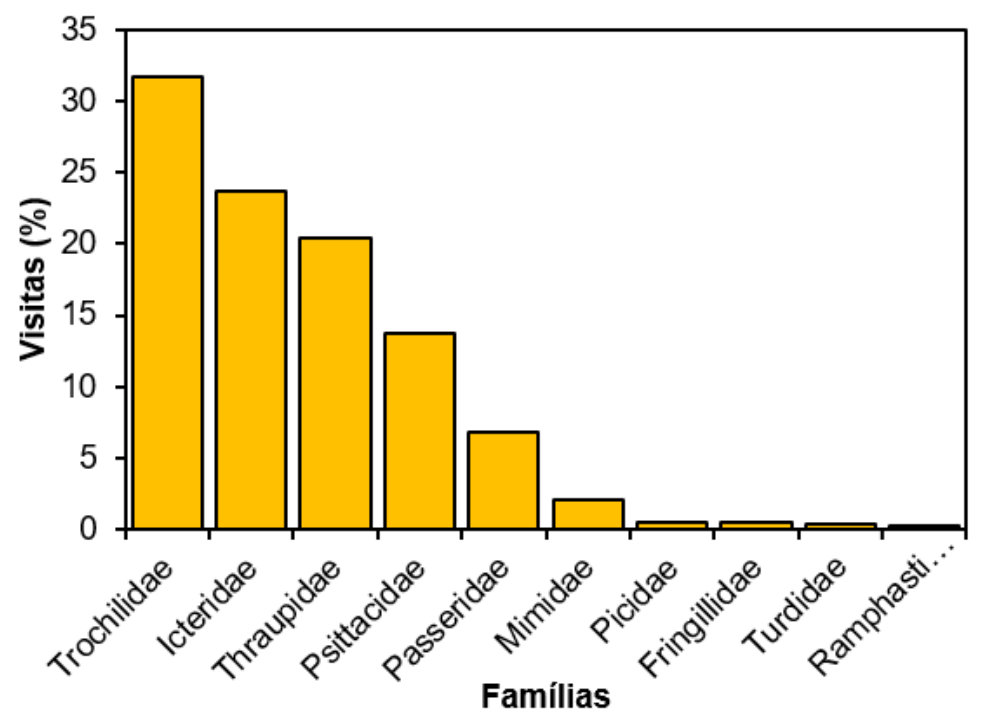

Fonte: Autores (2021).

As aves visitaram principalmente as copas arbóreas com intensidade máxima de floração (i.e., nota 4), mas a disponibilidade individual de flores, i.e., ao nível de copa arbórea, não teve um efeito estatisticamente significativo no número 
de visitas (Teste Qui-quadrado: $\chi^{2}=3,60, \mathrm{gl}=3, \mathrm{p}=0,308$; Figura 2). De acordo com a Teoria do Forrageamento Ótimo, os consumidores concentram o forrageio onde há oferta abundante de recursos, o que resulta em uma maior aquisição de energia com o mínimo de gasto (MacArthur \& Pianka, 1966). De fato, árvores de Erythrina dominguezii Hassl. (Fabaceae) com maior quantidade de flores foram mais visitadas pelas aves, e vice-versa (Ragusa-Netto, 2002). Embora nossas observações não se ajustem satisfatoriamente ao previsto pela teoria ecológica supracitada, ressaltamos que o ano e período dessa investigação foi bem seco. Isso sugere depleções acentuadas na disponibilidade geral de flores, frutos carnosos maduros, até artrópodes (Janzen, 1980; Ragusa-Netto, 2002; Silva, 2019). Nesse sentido, mesmo com poucas flores, e.g., notas 1 e 2, as copas de $H$. vellosoi oferecem oportunidades de aquisição de nutrientes e energia via consumo de pétalas e néctar durante o período mais seco do ano (cf. Franklin, 1999). Afinal, as pétalas florais são riquíssimas em carboidratos, aminoácidos, lipídios, carotenoides, flavonoides, vitaminas, ácidos orgânicos, minerais e antioxidantes (Mlcek \& Rop, 2011). Já o néctar é uma solução líquida contendo açúcares e outros componentes, fornecendo energia, nutrientes e água aos consumidores (Janzen, 1980; Heil, 2011; Fleming \& Kress, 2013). De fato, espécies de ipês produzem néctar com 23 a 30\% de concentração de açúcares (Barros, 2001; Souza et al., 2004; Ragusa-Netto, 2005), e são, assim, fontes consideráveis de energia para os visitantes florais.

Figura 3. Distribuição das visitas florais pelas aves de acordo com a intensidade de fenofase de floração (Índice de Fournier) de indivíduos de Handroanthus vellosoi na área urbana e periurbana de Ilha Solteira. Há sobreposição em pontos no plano gráfico, i.e., diferentes árvores com a mesma intensidade de floração foram igualmente visitadas.

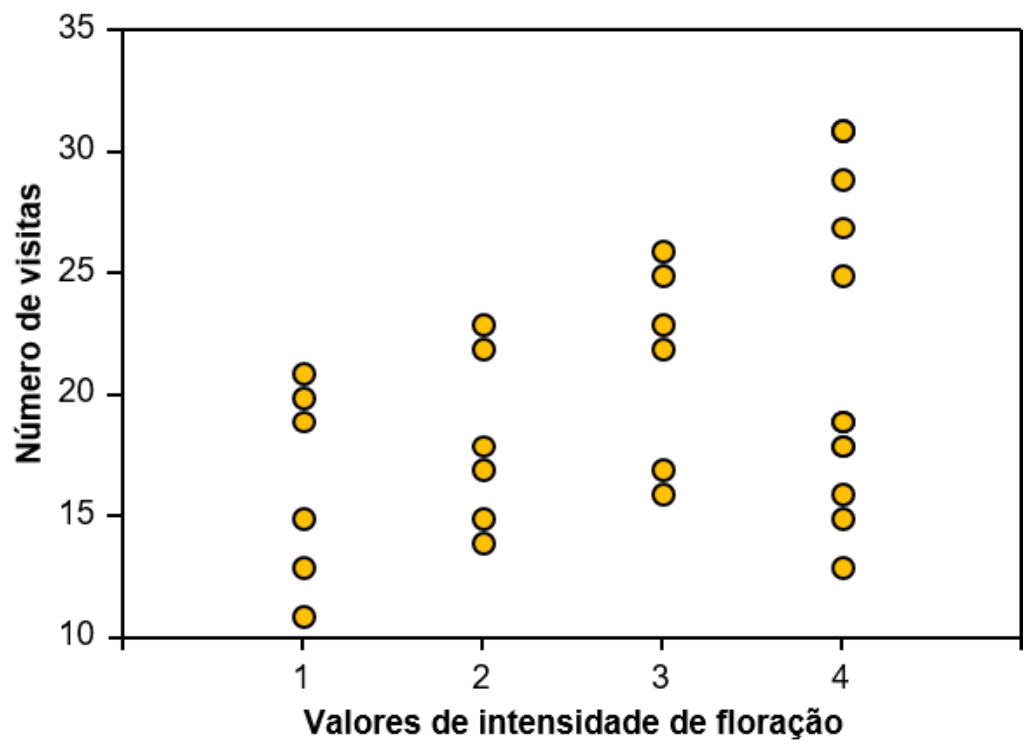

Fonte: Autores (2021).

As aves observadas visitando as flores de $H$. vellosoi pertencem a uma variedade de guildas tróficas (Tabela 1), como nectarívoros (beija-flores: Figura 4a-4e), frugívoros, insetívoros, frugívoros-granívoros (papagaios e periquitos: Figura 4f-4h), onívoros (sabiás-do-campo: Figura 4i; pardais: Fig. 4j; pássaros-preto: Figura 4k-4m), nectarívoros-insetívoros (fim-fim: Figura 3n), granívoros (coleirinha: Figura 4o; canário: Figura 4p) e frugívoros-insetívoros (sanhaços: Figura 4q-4r). Claramente, o sistema interativo aves-flores aqui abordado envolve um fenômeno de forrageamento oportunista, já que aves não nectarívoras interagiram consideravelmente com as flores de H. vellosoi (sensu Franklin, 1999). Isso reforça a ideia de obtenção de vantagens nutricionais e de aquisição de energia em um período crítico de escassez de recursos; i.e., aves não nectarívoras usualmente forrageiam em flores na estação seca (Pizo, 1996; Franklin, 1999; Ragusa-Netto, 2002; 2005; Silva, 2019). 
Research, Society and Development, v. 10, n. 15, e414101522982, 2021

(CC BY 4.0) | ISSN 2525-3409 | DOI: http://dx.doi.org/10.33448/rsd-v10i15.22982

Figura 4. Aves que interagem ou interagindo com as flores de Handroanthus vellosoi na área urbana e periurbana de Ilha Solteira. a) Polytmus guainumbi; b) Heliomaster furcifer; c) Chlorostilbon lucidus; d) Eupetomena macroura; e) Hylocharis chrysura; f) Brotogeris chiriri; g) Amazona aestiva; h) Eupsittula aurea; i) Mimus saturninus; j) Passer domesticus; k) Cacicus haemorrhous; 1) Icterus pyrrhopterus; m) Gnorimopsar chopi; n) Coereba flaveola; o) Sporophila leucoptera; p) Sicalis flaveola; q) Stilpnia cayana; r) Thraupis sayaca.

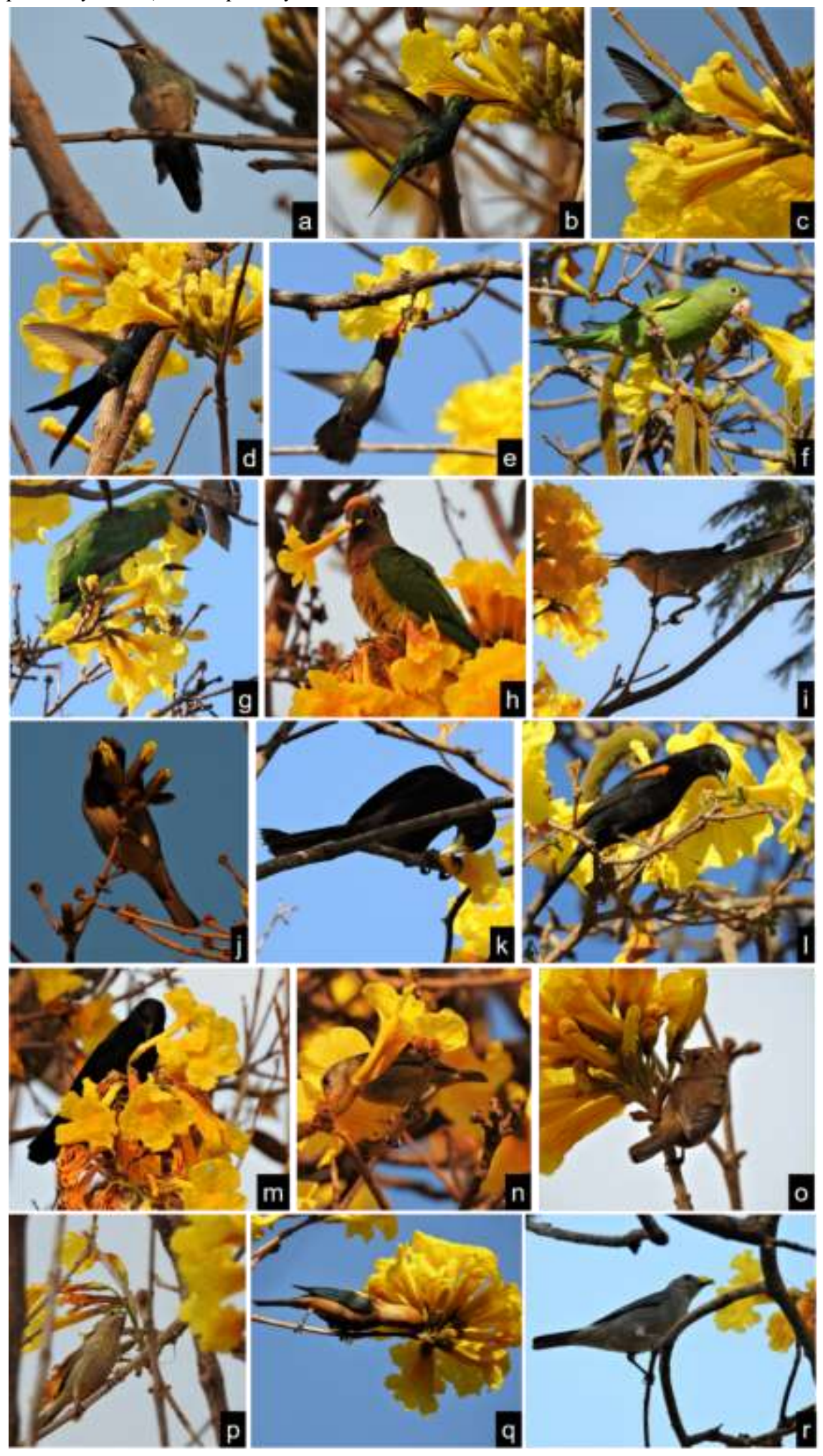

Fonte: Autores (2021). 
Ressaltamos que outros fatos ecologicamente importantes emergem dessa atratividade de guildas variadas. Por exemplo, os beija-flores, aves nectarívoras especializadas (Tabela 1), visitam flores de múltiplas espécies vegetais e promovem a polinização, potencialmente o fluxo de pólen e genes entre as plantas (Janzen 1980; Fleming \& Kress, 2013; Dalsgaard et al., 2021), inclusive na área urbana (Maruyama et al., 2019). Os demais consumidores também desempenham uma variedade de funções ecológicas de considerável valor. Aves granívoras são essencialmente predadores de sementes e, assim, regulam populações de plantas, muitas delas daninhas e invasoras (Whelan et al., 2015). Papagaios e periquitos predam e dispersam sementes e também polinizam flores (Ragusa-Netto, 2002; Blanco et al., 2018; Silva et al., 2020a). Onívoros, como os pássaros-preto, são muitas vezes considerados polinizadores de flores e dispersores de sementes (Pizo, 1996; Ragusa-Netto, 2002; Silva et al., 2020a). Aves de hábitos frugívoros-insetívoros, como as de Thraupidae, dispersam sementes e predam uma variedade de insetos (Manhães, 2003; Purificação et al., 2014; Pizo et al., 2021). Portanto, é plausível supor que, ao ofertar recursos florais, $H$. vellosoi contribui na manutenção de uma variedade de funções ecológicas que as aves de múltiplas guildas desempenham.

Com exceção dos papagaios, as aves de um modo geral se comportaram como pilhadores (Tabela 1), perfurando a base da corola ou o cálice para consumir o néctar (Figura 4b-4e; e 4l-4o). Várias espécies de aves também danificaram a corola (Tabela 1) ao remover e ingerir frações das pétalas repetidamente (Figura 4i, $4 \mathrm{j}$ e 4r). Os papagaios e periquitos colheram a flor com o bico e, segurando a mesma com um dos pés, vasculharam o cálice e a base da corola (Figura 4f-4h) para obter o néctar, comportando-se como predadores (Tabela 1). Os pássaros-preto (Icterídeos) às vezes atuaram como predadores (Tabela 1), pois, colheram a flor com o bico e pisaram nela com um dos pés para acessar o néctar enquanto vasculharam a corola e o cálice (Figura 4k). Tais comportamentos antagonísticos (ou florivoria em sentido amplo; cf. McCall \& Irwin, 2006) sugerem que há um padrão interativo consistente quando as aves visitam flores de ipês. Interações antagonistas similares aos que observamos foram amplamente detectadas em diferentes espécies de ipês (e.g., Ragusa-Netto, 2005; Melo et al., 2009; Parrini \& Pacheco, 2013; Mendes et al., 2017; Lunardi et al., 2019). Em última análise, a prevalência dessas interações antagônicas suporta a hipótese de que as cargas florais de ipês, muitas vezes maciças e sincronizadas, estão voltadas a saciar predadores (RagusaNetto, 2005) ou minimizar os impactos negativos advindos do consumo de pétalas e pilhagem de néctar. Em linhas gerais, a quantidade de flores é tão elevada que supera o consumo (Ragusa-Netto, 2005; Mendes et al., 2017), ou em meio a muitas flores, algumas escapam dos efeitos deletérios promovidos pelo forrageio antagônico dos animais (Efeito de Diluição; Hamilton, 1971; revisado em Tardin \& Alves, 2010), assegurando assim o sucesso reprodutivo. De fato, em bignoniáceas como os ipês, um percentual reduzido de flores é convertido em frutos, mas cabe notar que há um número considerável de sementes em cada fruto (e.g., Barros, 2001; Souza et al., 2004; Acra et al., 2012). Na verdade, há uma via de investigação futura aqui, pois, os visitantes antagônicos, destacando os beija-flores pilhadores, devem forçar muitos polinizadores a visitar mais flores, dentro e entre copas (e.g., Maruyama et al., 2012). Em hipótese, o sucesso reprodutivo de muitos ipês estaria indiretamente ligado às interações antagônicas.

Os beija-flores Polytmus guainumbi e Heliomaster furcifer também interagiram com as flores de $\mathrm{H}$. vellosoi de maneira não antagonista (Tabela 1). Estas aves às vezes pousaram em um galho, ou nas pétalas, defronte à abertura da corola (Figura 5a), e inseriram o bico no tubo florífero para acessar e consumir o néctar. Tal comportamento possibilita o contato do bico com os estames e estigma (visita legítima), o que potencialmente promove a polinização. Embora não muito frequente, há relatos de beija-flores potencialmente polinizando flores de Handroanthus ochraceus e Tabebuia aurea (Moura \& Correa, 2015; Mendes et al., 2017, respectivamente). Contudo, Mendonça \& Anjos (2005) presumiram que o tubo floral das flores de ipês (Tabebuia e Handroanthus) são longas e, portanto, impedem a polinização pelos beija-flores. Em outras palavras, esse atributo floral impele a pilhagem de néctar (Parrini \& Pacheco, 2013). Nossas observações aqui sugerem que uma maior atenção deve ser dada aos beija-flores com bicos mais longos (Figura 5 b e 5c), no sentido de averiguar se eles são potenciais 
polinizadores de representantes de Bignoniaceae, como os ipês. Isso porque, dentre os beija-flores observados, as duas espécies que visitaram as flores de H. vellosoi legitimamente são as que têm o bico mais alongado (Grantsau, 1988; compare as Figuras $5 \mathrm{~b}$ e $5 \mathrm{c}$ com a Figura $5 \mathrm{~d})$.

Figura 5. a) Um beija-flor (bico-reto-azul, Heliomaster furcifer) realizando uma visita legítima em uma flor de Handroanthus vellosoi na área periurbana de Ilha Solteira. b) Um beija-flor $H$. furcifer ilustra seu bico longo e reto. c) Um beija-flor Polytmus guainumbi ilustra seu bico longo e encurvado. d) Um beija-flor Eupetomena macroura, cujo bico é 10 a 10,5 mm menor do que o de P. guainumbi e H. furcifer, respectivamente (Grantsau, 1988).

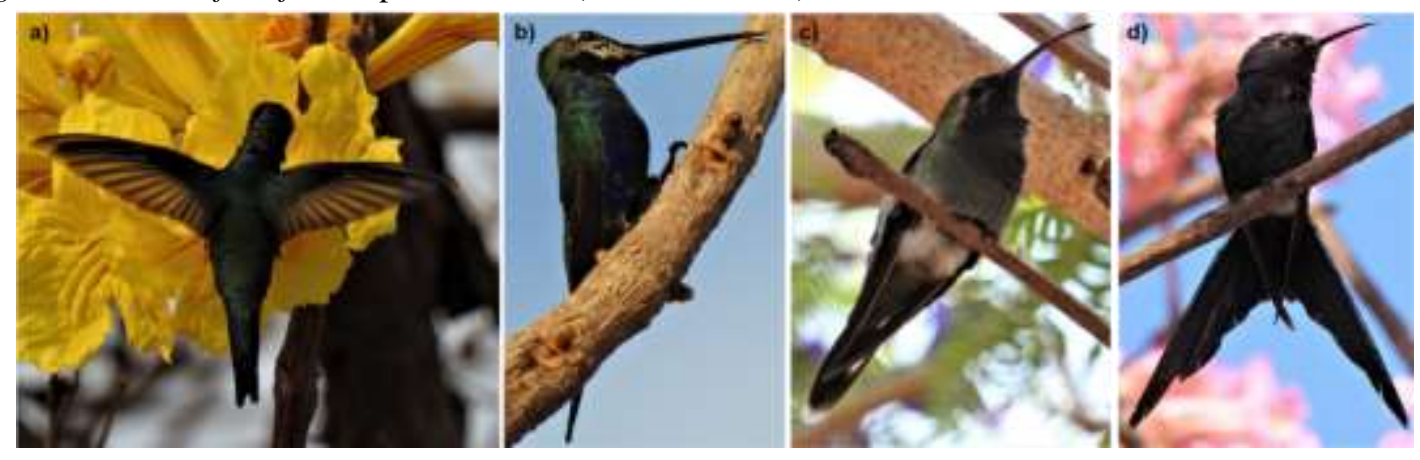

Fonte: Autores (2021).

A curva de rarefação de espécies, calculada com base em 598 indivíduos detectados nas 30 sessões de observação, não atingiu uma assíntota (Figura 6). A predição da riqueza de espécies diferiu entre os estimadores. Bootstrapping, seguido pelo estimador Chao2, previram os menores valores, i.e., 34,62 e 36,41, respectivamente. Já os estimadores Jackknife 1 e Jackknife 2, previram maiores valores, i.e., 38,73 e 42,59, respectivamente. Tais valores revelam o quão $H$. vellosoi pode ser importante na atração de aves, pois, sugere uma diversidade ainda maior de espécies associadas a suas flores na área urbana e periurbana. Se consideramos os beija-flores, comumente envolvidos em uma rede de interações generalizada com as flores na área urbana (Maruyama et al., 2019), as estimativas fazem sentido, pois, ao menos outras 17 espécies de Trochilidae tem distribuição geográfica abrangendo a área de estudo (e.g., Sick, 1997; Willis \& Oniki, 2003; Fogden et al., 2014; Mello et al., 2020). Mais ainda, dentre as 10 espécies de bignoniáceas avaliadas quanto ao valor de importância às aves visitantes florais, cinco apresentaram valores positivos de PC1 (Figura 7). Nesse cenário, H. vellosoi obteve o segundo maior valor: o primeiro foi H. impetiginosus, ipê arbóreo cuja importância para as aves no âmbito urbano foi recentemente evidenciada (veja Lunardi et al., 2019). Portanto, H. vellosoi cumpre um papel significante para a biodiversidade na perspectiva da urbanização, como sintetizado a seguir.

\section{Considerações Finais}

A abordagem na interação planta-animal aqui realizada mostrou que $H$. vellosoi é uma árvore endêmica do Brazil importante para as aves que visitam flores em ambientes urbanizados. A variedade taxonômica desses vertebrados e a frequência com a qual relacionam-se troficamente, sobretudo de maneira antagonista, com as flores, sustentam tal asserção. Cabe notar que a falta de estabilização na curva de rarefação, bem como os estimadores, sugere que $H$. vellosoi pode interagir com uma variedade ainda maior de espécies, o que eleva a sua relevância no âmbito urbano. Ressalta-se ainda que as aves de diferentes guildas tróficas frequentemente atraídas pelas flores são reconhecidas pelos papéis-chaves que cumprem em escala de ecossistemas. Nesse ponto, destacamos os beija-flores nectarívoros como polinizadores especializados, bem como espécies de Psittacidae, Icteridae e Thraupidae, as quais também polinizam flores, dispersam e predam sementes, ou então, predam insetos. 
Figura 6. Curva de rarefação baseada nas aves visitantes das flores de Handroanthus vellosoi na área urbana e periurbana de Ilha Solteira. Os pontos amarelos fechados representam a riqueza dos táxons, e as barras de erro indicam os desvios padrão.

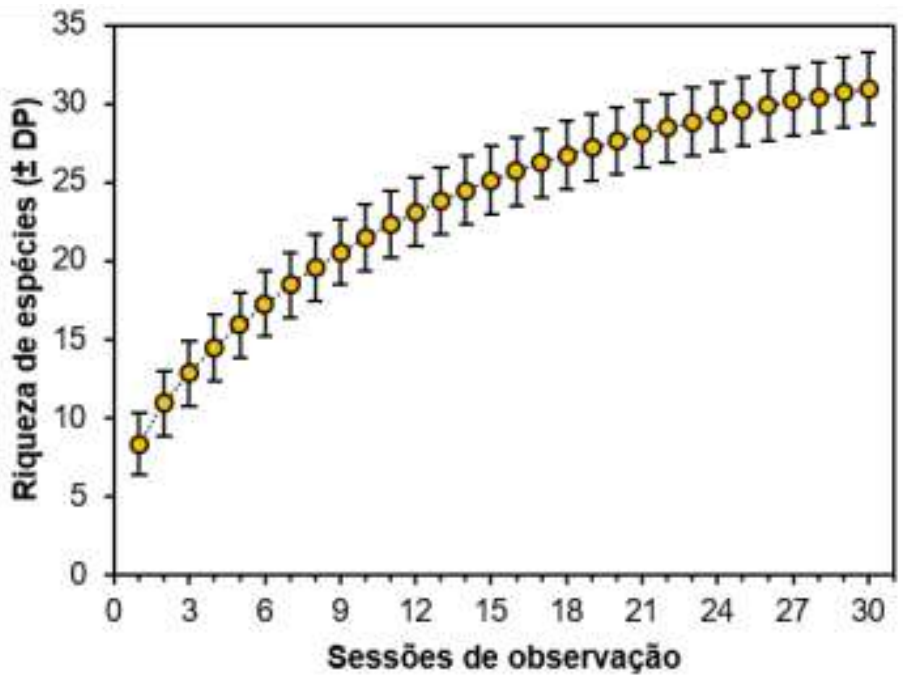

Fonte: Autores (2021).

Figura 7. Importância relativa das espécies de bignoniáceas para a comunidade de aves que visitam suas flores na área urbana e periurbana de Ilha Solteira. A análise considerou 7049 visitas florais realizadas por 51 espécies de aves.
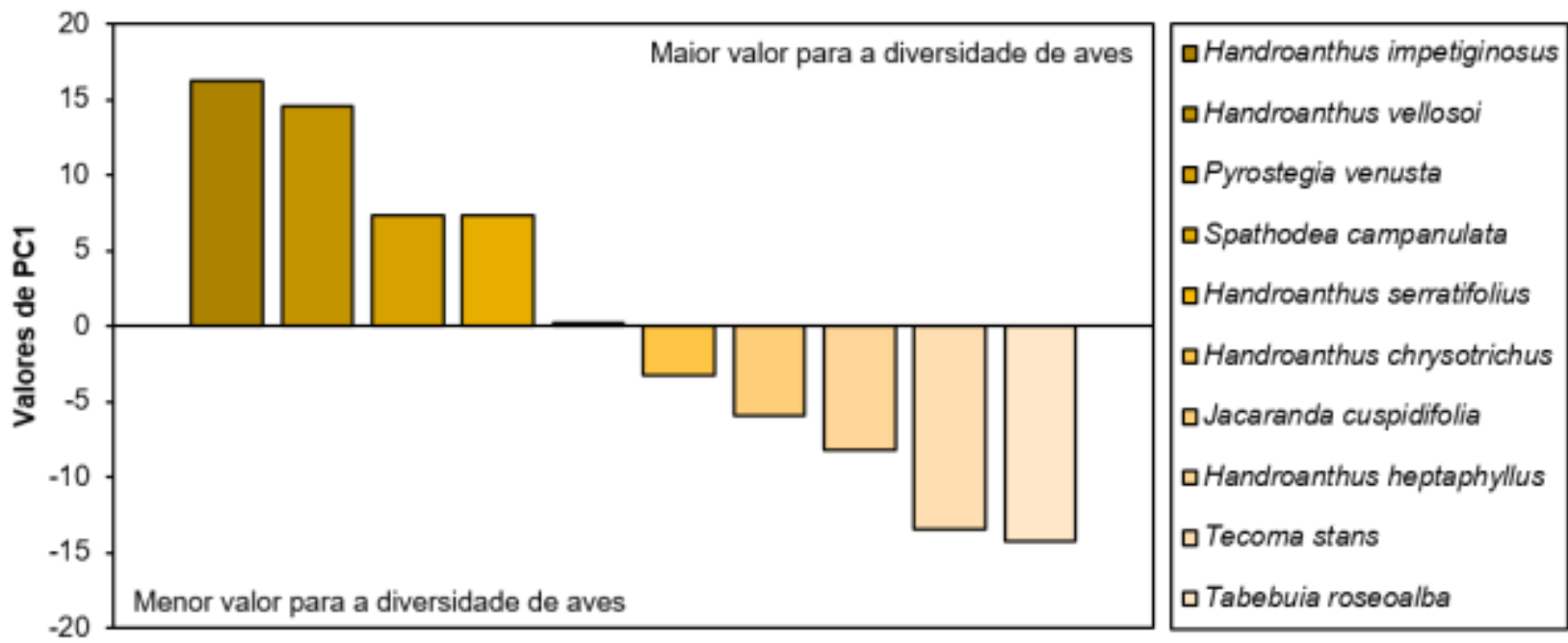

Fonte: Autores (2021).

Em adição, $H$. vellosoi floresce no auge da estação seca e, via provisão de pétalas (nutrientes) e néctar (energia), tem o potencial de tamponar os impactos negativos da escassez geral de alimento às aves (e.g., de flores, frutos carnosos maduros e artrópodes) nesse período tão crítico do ano. Em última análise, nossa abordagem quantitativa reforça que $H$. vellosoi tem um considerável valor, ou então influência, ao nível de comunidade de aves que interagem com flores, muitas vezes de maneira oportunista, na área urbana e periurbana, especificamente comparado a outras bignoniáceas. Portanto, a interação plantaanimal aqui abordada sugere consistentemente que o ipê-amarelo $H$. vellosoi deve ser selecionado e incorporado a projetos de esverdeamento urbano, sobretudo em regiões onde ele é nativo no Brasil. Afinal, via atração de uma variedade de aves, esta bignoniácea arbórea efetivamente ajuda a promover e manter a biodiversidade na cidade.

Nós ainda recomendamos novas avaliações de aves e outros animais interagindo com diferentes espécies vegetais em áreas urbanizadas. Em um cenário de crescimento urbano exacerbado e impactos negativos associados, tal enfoque ecológico é 
consistente com os objetivos da biologia da conservação e sustentabilidade em tornar as cidades cada vez mais amigas da biodiversidade ou biofílicas.

\section{Agradecimentos}

Este estudo é parte de um projeto pessoal do primeiro autor e recebeu um aporte financeiro da FAPEMIG e CAPES entre 2009 e 2013. A CAPES concedeu bolsa de Pós-graduação ao segundo e sexto autor. O primeiro autor dedica este artigo a sua mãe (in memoriam).

\section{Referências}

Ab'Sáber, A. N. (2012). Os domínios de natureza no Brasil: potencialidades paisagísticas. Ateliê Editorial.

Acra, L. A., Carvalho, S. M. \& Cervi, A. C. (2012). Biologia da polinização e da reprodução de Handroanthus chrysotrichus (Mart. ex DC) Mattos (Bignoniaceae Juss.). Estudo de Biologia, 34(82), 45-49.

Altman, J. (1974). Observational study of behavior: sampling methods. Behaviour, 49, 227-267.

Alvey, A. A. (2006). Promoting and preserving biodiversity in the urban forest. Urban Forestry \& Urban Greening, 5, $195-201$.

Angel, S., Blei, A. M., Civco, D. L. \& Parent, J. (2012). Atlas of Urban Expansion. Lincoln Institute of Land Policy.

Apfelbeck, B., Snep, R. P. H., Hauck, T. E., Ferguson, J., Holy, M., Jakoby, C., Macivor, J. S., Schär, L., Taylor, M. \& Weisser, W. W. (2020). Designing wildlife-inclusive cities that support human-animal co-existence. Landscape and Urban Planning, 200, 103817.

Barros, M. G. (2001). Pollination ecology of Tabebuia aurea (Manso) Benth. And Hook. and T. ochracea (Cham.) Standl. (Bignoniaceae) in Central Brazil Cerrado vegetation. Revista Brasileira de Botânica, 24(3), 255-261.

Blanco, G., Hiraldo, F. \& Tella, J.L. (2018). Ecological functions of parrots: an integrative perspective from plant life cycle to ecosystem functioning. Emu, $118,36-49$

Chao, A. (1987). Estimating the population size for capture-recapture data with unequal catchability. Biometrics, 43, $783-791$.

Chazdon, R. L., Harvey, C. A., Komar, O., Griffith, D. M., Ferguson, B. G., Martínez-Ramos, M., Morales, H., Nigh, R., Soto-Pinto, L., Breugel, M. V. \& Philpott, S. M. (2009). Beyond reserves: a research agenda for conserving biodiversity in human-modified tropical landscapes. Biotropica, $41,142-153$.

Companhia Energética de São Paulo. (1986). Lista básica de espécies vegetais usadas em paisagismo. CESP.

Costanza, R., d'Arge, R., Groot, R.d., Farberl, S. \& Grasso, M. (1997). The value of the world's ecosystem services and natural capital. Nature, 387, 253-260.

Dalsgaard, B., Maruyama, P. K., Sonne, J., Hansen, K., Zanata, T. B., Abrahamczyk, S. et al. (2021). The influence of biogeographical and evolutionary histories on morphological trait-matching and resource specialization in mutualistic hummingbird-plant networks. Functional Ecology, 35, $1120-1133$.

Del-Claro, C. \& Torezan-Silingard, H. M. (2021). Plant-animal interactions: source of biodiversity. Springer.

Fernandez, F. (2016). Os mastodontes de barriga cheia e outras histórias: crônicas de biologia e conservação da natureza. Technical Books.

Fleming, T. H. \& Kress, W. J. (2013). The ornaments of life: coevolution and conservation in the tropics. University of Chicago Press.

Fogden, M., Taylor, M. \& Williamson, S. L. (2014). Hummingbirds: a life-size guide to every species. Harper Collins.

Fournier, L. A. (1974). Um método cuantitativo para la medición de características fenológicas em árboles. Turrialba, 24, 422-423.

Franklin, D. C. (1999). Opportunistic nectarivory: an annual dry season phenomenon among birds in monsoonal Northern Australia. Emu, 99, $135-141$.

Galetti, M. (2002). Métodos para avaliar a dieta de psitacídeos. In: Galetti, M. \& Pizo, M. Ecologia e conservação de psitacídeos no Brasil. Melopsittacus Publicações Científicas, pp. 113-122.

Gandolphi, G. \& Bittencourt Jr., N. S. (2010). Sistema reprodutivo do Ipê-branco - Tabebuia roseo-alba (Ridley) Sandwith (Bignoniaceae). Acta Botânica Brasílica, 24(3), 840-851.

Gentry, A. H. (1974). Flowering phenology and diversity in tropical Bignoniaceae. Biotropica, 6, 64-68

Goddard, M. A., Dougill, A. J. H. \& Benton, T. G. (2010). Scaling up from gardens: biodiversity conservation in urban environments. Trends in Ecology and Evolution, 25, 90-98.

Grantsau, R. (1988). Os beija-flores do Brasil: uma chave de identificação para todas as formas de beija-flores do Brasil. Expressão e Cultura. 
Güneralp, B. \& Seto, K. (2013). Futures of global urban expansion: uncertainties and implications for biodiversity conservation. Environmental Research Letters, 8, 014025 .

Hamilton, W. D. (1971). Geometry for the selfish herd. Journal of Theoretical Biology, 31, 295-311.

Harper, D. A. T. (1999). Numerical Palaeobiology: computer-based modelling and analysis of fossils and their distributions. John Wiley \& Sons.

Heil, M. (2011). Nectar: generation, regulation and ecological functions. Trends in Plant Science, 16, 191-200.

Instituto Florestal. (2020). Inventário florestal do Estado de São Paulo: mapeamento da cobertura vegetal nativa. Governo do Estado de São Paulo, Secretaria de Infraestrutura e Meio Ambiente do Estado de São Paulo.

Ives, C. D., Lentini, P. E., Threalfall, C. G. et al. (2016). Cities are hotspots for threatened species. Global Ecology and Biogeography, 25(1), 117-126.

Janzen, D. H. (1980). Ecologia vegetal nos Trópicos. EDUSP.

Jones, B.A. (2021). Planting urban trees to improve quality of life? The life satisfaction impacts of urban afforestation. Forest Policy and Economics, 125, 102408 .

Kark, S., Allnutt, T. F., Levin, N., Manne, L. L. \& Williams, P. H. (2006). The role of transitional areas as avian biodiversity centres. Global Ecology and Biogeography, 16, 187-196.

Knapp, S., Aronson, M.F., Carpenter, E., Herrera-Montes, A., Jung, K., Kotze, D.J. et al. (2021). A research agenda for urban biodiversity in the global extinction crisis. Bioscience, 71, 268-279.

Kowarik, I. (2011). Novel urban ecosystems, biodiversity, and conservation. Environmental Pollution, 159, 1974-1983.

Lepczyk, C. A., Aronson, M. F. J., Evans, K. L., Goddard, M. A., Lerman, S. B. \& MacIvor, J. S. (2017). Biodiversity in the city: fundamental questions for understanding the ecology of urban green spaces for biodiversity conservation. Bioscience, 67, 799-807.

Liu, Z., He, C., Zhou, Y. \& Wu, J. (2014). How much of the world's land has been urbanized, really? A hierarchical framework for avoiding confusion. Landscape Ecology, 29, 763-771.

Locke, D. \& Baine, G. (2015). The good, the bad, and the interested: how historical demographics explain present-day tree canopy, vacant lot and tree request spatial variability in New Haven, CT. Urban Ecosystems, 18, 391-409.

Lohmann, L. G. (2020). Handroanthus in Flora do Brasil 2020. Jardim Botânico do Rio de Janeiro. Disponível em: <http://floradobrasil.jbrj.gov.br/reflora/floradobrasil/FB114100>. Acesso em: 03 set. 2021.

Lorenzi, H. (2008). Árvores brasileiras: manual de identificação e cultivo de plantas arbóreas nativas do Brasil. Instituto Plantarum.

Lunardi, V. O., Silva, E. E. M., Silva, S. T. A. \& Lunardi, D. G. (2019). Handroanthus impetiginosus (Bignoniaceae) as an important floral resource for synanthropic birds in the Brazilian Semiarid. Oecologia Australis, 23(1), 137-144,

Machado, C. G. \& Rocca, M. A. (2010). Protocolos para estudo de polinização por aves. In: Von Matter, S., Straube, F. C., Accordi, I. A., Picacentini, V. Q. \& Candido Jr., F. F. (Orgs.). Ornitologia e conservação: ciência aplicada, técnica de pesquisa e levantamento. Technical Books, pp. $473-489$.

MacArthur, R. H. \& Pianka, E. R. (1966). On optimal use of a patchy environment. The American Naturalist, 100, $603-609$.

Magurran, A. E. (2019). Medindo a diversidade biológica. UFPR.

Manhães, M. A. (2003). Dieta de Traupíneos (Passeriformes, Emberizidae) no Parque Estadual do Ibitipoca, Minas Gerais, Brasil. Iheringia (Série Zoológica), 93(1), 59-73.

Marcon, A. P. (2016). Interação dos beija-flores e seus recursos florais em um ambiente antropizado no sul do Brasil. Atualidades Ornitológicas, 193 , 18-24.

Maruyama, P. K., Bonizário, C., Marcon, A. P., D'Angelo, G., Silva, M. M., Silva Neto, E. N. \& Marçal Júnior, O. (2019). Plant-hummingbird interaction networks in urban areas: generalization and the importance of trees with specialized flowers as a nectar resource for pollinator conservation. Biological Conservation, 230, 187-194.

Maruyama, P. K., Custódio, L. N. \& Oliveira, P. E. (2012). When hummingbirds are the thieves: visitation effect on the reproduction of Neotropical snowbell Styrax ferrugineus Nees \& Mart (Styracaceae). Acta Botânica Brasilica, 26, 58-64.

Mascaró, L. \& Mascaró, J. (2005). Vegetação Urbana. Mais Quatro.

McCall, A. C. \& Irwin, R. E. (2006). Florivory: the intersection of pollination and herbivory. Ecology Letters, 9, $1351-1365$.

McDonald, R. I., Mansur, A. V., Ascensão, F., Colbert, M’. L., Crossman, K., Elmqvist, T., Gonzalez, A., Güneralp, B., Haase, D., Hamann, M., Hillel, O., Huang, K., Kahnt, B., Maddox, D., Pacheco, A., Pereira, H. M., Seto, K. C., Simkin, R., Walsh, B., Werner, A. S. \& Ziter, C. (2019). Research gaps in knowledge of the impact of urban growth on biodiversity. Nature Sustainability, 3, 16-24.

Melo, C., Oliveira, A. D., Borges, C. A., Ribeiro, G. \& Tavares, J. (2009). Impact of Forpus xanthopterygius (Spix, 1824) (Aves: Psittacidae) on flowers of Handroanthus serratifolius (Vahl.) S. O. Grose (Bignoniaceae). Brazilian Journal of Biology, 69(4), 1149-1151.

Melo, F. P. L., Arroyo-Rodríguez, V., Fahrig, L., Martínez-Ramos, M. \& Tabarelli, M. (2013). On the hope for biodiversity-friendly tropical landscapes. Trends in Ecology and Evolution, 28, 461-468. 
Mello, D. J. N., Mello, G. J. N., Mallet-Rodrigues, F. \& Lima, L. M. (2020). Aves do sudeste do Brasil: guia de identificação. Gabriel Jorge Menezes Mello.

Mendes, D. O. F., Mendes, L. F. P., Souza, E. O. \& Aoki, C. (2017). Flores de paratudo (Tabebuia aurea) (Bignoniaceae) como recurso alimentar para aves no Pantanal Sul, Brasil. Boletim do Museu Paraense Emílio Goeldi (Ciências Naturais), 12(2), 295-299,

Mendonça, L. B. \& Anjos, L. (2005). Beija-flores e seus recursos florais em uma área urbana do sul do Brasil. Revista Brasileira de Zoologia, $22,51-59$.

Mlcek, J. M. \& Rop, O. (2011). Fresh edible flowers of ornamental plants - a new source of nutraceutical foods. Trends in Food Science \& Technology, 22, 561-569.

Moura, A. S. \& Corrêa, B. S. (2015). Ornitofilia em Handroanthus ochraceus (Cham.) Mattos (Bignoniaceae) em um fragmento de floresta decidual do norte de Minas Gerais. Regnellea Scientia, 2(1), 23-29.

Myers, N., Mittermeier, R. A., Mittermeier, C. G., da Fonseca, G. A. B. \& Kent, J. (2000). Biodiversity hotspots for conservation priorities. Nature, 403, 853858.

Pacheco, J. F., Silveira, L. F., Aleixo, A., Agne, C. E., Bencke, G. A., Bravo, G. A, Brito, G. R. R., Cohn-Haft, M., Mauricio, G. N., Naka, L. N., Olmos, F., Posso, S., Lees, A. C., Figueiredo, L. F. A., Carrano, E., Guedes, R. C., Cesari, E., Franz, I., Schunck, F. \& Piacentini, V. Q. (2021). Annotated checklist of the birds of Brazil by the Brazilian Ornithological Records Committee - second edition. Ornithology Research, 29(2).

Parrini, R. \& Pacheco, J. F. (2013). Comportamentos de forrageamento das aves na exploração de recursos florais de Tabebuia heptaphylla (Bignoniaceae) no Pantanal de Mato Grosso, Brasil. Atualidades Ornitológicas, 171: 4-7.

Pizo, M. A. (1996). Feeding ecology of two Cacicus species (Emberizidae, Icterinae). Ararajuba, 4(5), 87-92.

Pizo, M. A., Morales, J. M., Ovaskainen, O. \& Carlo, T. A. (2021). Frugivory specialization in birds and fruit chemistry structure mutualistic networks across the Neotropics. The American Naturalist, 197, 236-249.

Power, M. E. (1992). Top-down and bottom-up forces in food webs: do plants have primacy. Ecology, 73(3), $733-746$.

Purificação, K. N., Pascotto, M. C., Pedroni, F., Pereira, J. M. N. \& Lima, N. A. (2014). Interactions between frugivorous birds and plants in savanna and forest formations of the Cerrado. Biota Neotropica, 14, e20140068.

Ragusa-Netto, J. (2002). Exploitation of Erythrina dominguezii Hassl. (Fabaceae) nectar by perching birds in a dry forest in western Brazil. Brazilian Journal of Biology, 62, 877-883.

Ragusa-Netto, J. (2005). Extensive consumption of Tabebuia aurea (Manso) Benth. \& Hook. (Bignociaceae) nectar by parrots in a tecoma savanna in the souther Pantanal (Brazil). Brazilian Journal of Biology, 65(2), 339-344.

Rees, W. \& Wackernagel, M. (1996). Urban ecological footprints: why cities cannot be sustainable-and why they are key for sustainability. Environmental Impact Assessment Review, 16, 223-248.

Rodrigues, A. S. L., Andelman, S. J., Bakarr, M. I., Boitani, L., Brooks, T. M., Cowling, R. M., Fishpool, L. D. C., da Fonseca, G. A. B., Gaston, K. J., Hoffmann, M., Long, J. S., Marquet, P. A., Pilgrim, J. D., Pressey, R. L., Schipper, J., Sechrest, W., Stuart, S. N., Underhill, L. G., Waller, R. W., Watts, M. E. J. \& Yan, X. (2004). Effectiveness of the global protected area network in representing species diversity. Nature, 428, 640-643.

Sartori, R. A., Martins, G. A. C., Zaú, A. S. \& Brasil, L. S. C. (2019). Urban afforestation and favela: a study in a community of Rio de Janeiro. Urban Forestry \& Urban Greening, 40, 84-92

Schuldt, A., Assmann, T., Brezzi, M., Buscot, F., Eichenberg, D., Gutknecht, J., Härdtle, W., He, J. S , Klein, A. M., Kühn, P., Liu, X., Ma, K., Niklaus, P. A., Pietsch, K. A., Purahong, W., Scherer-Lorenzen, M., Schmid, B., Scholten, T., Staab, M., Tang, Z., Trogisch, S., von Oheimb, G., Wirth, C., Wubet, T., Zhu, C.-D., \& Bruelheide, H. (2018). Biodiversity across trophic levels drives multifunctionality in highly diverse forests. Nature Communications, 9(1), 1-10.

Shaffer, H. B. (2018). Urban biodiversity arks. Nature Sustainability, 1, 725-727.

Sick, H. (1997). Ornitologia Brasileira. Nova Fronteira.

Silva, P. A. (2019). Flowers eating by the Toco Toucan (Ramphastos toco) in an anthropogenic landscape during the dry season. Ornitología Neotropical, 30, 51-55.

Silva, P. A., Silva, L. L. \& Brito, L. (2020a). Using bird-flower interactions to select native tree resources for urban afforestation: the case of Erythrina velutina. Urban Forestry \& Urban Greening, 51, 126677.

Silva, J. J. S., de Oliveira, M. T. P., Cruz-Neto, O., Tabarelli, M. \& Lopes, A. V. (2020b). Plant-pollinator interactions in urban ecosystems worldwide: A comprehensive review including research funding and policy actions. Ambio, 50, 884-900.

Smith, E. P. \& Van Belle, G. (1984). Nonparametric estimation of species richness. Biometrics, 40, 119-129.

Souza, D. A. S., Lenzi, M. \& Orth, A. I. (2004). Contribuição à ecologia da polinização de Tabebuia pulcherrima (Bignoniaceae) em área de restinga, no sul de Santa Catarina. Biotemas, 17(2), 47-66.

Tardin, R. O. \& Alves, M. A. S. (2010). Custos e benefícios da vida em grupo em um contexto de forrageamento em vertebrados: uma abordagem das tendências de publicações científicas em 50 anos de estudos. Oecologia Australis, 14(4), 911-958. 
Research, Society and Development, v. 10, n. 15, e414101522982, 2021

(CC BY 4.0) | ISSN 2525-3409 | DOI: http://dx.doi.org/10.33448/rsd-v10i15.22982

Threlfall, C. G., Mata, L., Mackie, J. A., Hahs, A. K., Stork, N. E., Williams, N. S. G., \& Livesley, S. J. (2017). Increasing biodiversity in urban green spaces through simple vegetation interventions. Journal of Applied Ecology, 54, 1874-1883.

UNPD - United Nations Population Division. (2018). World Urbanization Prospects: The 2018 Revision.

Vieira, R. R. S., Pressey, R. L. \& Loyola, R. (2019). The residual nature of protected areas in Brazil. Biological Conservation, 233, 152-161.

Vitali, M. I. \& Machado, V. L. L. (1995). Entomofauna visitante das flores de Tabebuia chrysotricha (Mart.) Standl (Bignoniaceae). Anais da Sociedade de Entomologia do Brasil, 24, 77-88.

Vitorino, B. D., Frota, A. V. B. \& Maruyama, P. K. (2021). Ecological determinants of interactions as key when planning pollinator-friendly urban greening: A plant-hummingbird network example. Urban Forestry \& Urban Greening, 64, 127298.

Whelan, C. J., Şekercioğlu, C. H. \& Wenny, D. G. (2015). Why birds matter: from economic ornithology to ecosystem services. Journal of Ornithology, 156 (Supplement 1), 227-238.

Willis, E. O. (2002). Birds at Eucalyptus and other flowers in Southern Brazil: a review. Ararajuba, 10(1), 43-66.

Willis, E. O. \& Oniki, Y. (2003). Aves do Estado de São Paulo. Divisa.

Wilson, E. O. (2016). Half-Earth: our planet's fight for life. Liveright Publishing Corporation.

Zhang, J., Qian, H., Girardello, M., Pellissier, V., Nielsen, S. E. \& Svenning, J.-C. (2018). Trophic interactions among vertebrate guilds and plants shape global patterns in species diversity. Proceedings of the Royal Society B: Biological Sciences, 285, 20180949. 